\title{
Erratum to: Pushing the Paradigm: Addressing Controversies over LGBTQ Intimate Partner Violence?
}

\author{
C. E. B. Cannon ${ }^{1}$ - F. P. Buttell ${ }^{2}$
}

Published online: 28 November 2016

(C) Springer Science+Business Media New York 2016

Erratum to: J Fam Viol

DOI: 10.1007/s10896-016-9883-2

The original version of this article unfortunately contained a mistake. The original title "The Social Construction of Roles in Intimate Partner Violence: Is the Victim/Perpetrator Model the only Viable one?" is not correct. The correct title is "Pushing the Paradigm: Addressing Controversies over LGBTQ Intimate Partner Violence?" as reflected above.

The online version of the original article can be found at http://dx.doi. org/10.1007/s10896-016-9883-2.

C. E. B. Cannon

ccannon3@tulane.edu

1 School of Liberal Arts, Tulane University, 6823 St. Charles Ave, New Orleans, LA 70118, USA

2 School of Social Work, Tulane University, New Orleans, LA, USA 